\title{
Adaptação da aprendizagem ativa para o ensino remoto: proposta para a disciplina de Gestão Empresarial da UFPA
}

DOI: 10.37702/2175-957X.COBENGE.2021.3711

Gabriel Villas Boas de Amorim Lima - gabrielvbal@yahoo.com.br Universidade Federal do Pará

Travessa Angustura 1402

66080-180 - Belém - PA

Renato Martins das Neves - neves@ufpa.br

Universidade Federal do Pará

trav. 3 de maio 1295

66060-600 - Belém - PA

Elaine Cristina de Souza Angelim - profufpa@gmail.com

Universidade Federal do Pará

Passagem São Pedro 262

66070-740 - Belém - PA

Resumo: A pandemia do COVID-19 tornou o ensino remoto uma realidade na educação, propondo um desafio latente àqueles inseridos no contexto da aprendizagem ativa; contudo, não se identificou ainda como gerenciar essa adaptação do mundo presencial para o digital sem comprometer os objetivos da aprendizagem. Assim, este trabalho objetivou investigar quais adaptações na Aprendizagem baseada em Problemas (PBL) são necessárias para a condução de uma disciplina de Gestão Empresarial de forma remota. O método consistiu na planejamento do PBL em um turma presencial (pré-pandemia) e outra remota (durante a pandemia) em quatro etapas: I) apresentação do PBL; II) Identificação de problemas; III) Aplicação do PBL e; IV) Apresentação de resultados do PBL. O ambientes presencial e remoto foram avaliados nestas quatro etapas a partir das dimensões física, funcional, temporal e relacional - buscando identificar as diferenças em procedimentos, atitudes e atividades inerentes ao aprendizado. Os resultados indicaram que as principais adaptações estão relacionadas à experiência do ambiente de prática profissional - como visitas aos canteiros de obras, a interação com profissionais geograficamente distantes por meio de videochamadas, a maior necessidade do gerenciamento de tempo entre atividades acadêmicas e pessoais, além da empatia com acontecimentos pessoais alheios. 


\section{(C) COBENGE

Competências como autonomia e empatia são potencializadas no ambiente virtual, enquanto que a comunicação necessita de maior planejamento sem invadir o espaço pessoal do aluno. O estudo concluiu que a adaptação da aprendizagem ativa para o ambiente virtual é possível desde que conhecidas e integradas as condições socioeconômicos e socioemocionais em que se encontram os participantes.

Palavras-chave: COVID-19. PBL. Prática Profissional. Empatia. 


\section{ADAPTAÇÃO DA APRENDIZAGEM ATIVA PARA O ENSINO REMOTO: PROPOSTA PARA A DISCIPLINA DE GESTÃO EMPRESARIAL DA UFPA}

\section{INTRODUÇÃO}

A Era da informação recondicionou o desenvolvimento dos engenheiros do século XXI. A figura do engenheiro extrapolou o caráter tecnicista e demanda competências gerenciais que sempre desenvolveu na prática, ainda que outrora invisibilizadas durante sua formação acadêmica (LIMA et al., 2017). Dessa forma, busca-se atualmente reconciliar teoria e prática em uma tentativa de desenvolver competências que direcionem a educação em engenharia a atuar de modo mais coeso às demandas por profissionais com habilidades transversais (BARBALHO et al., 2017).

Entretanto, tais esforços são pouco efetivos quando aplicados por métodos tradicionais de ensino-aprendizagem, dos quais se pressupõe a pura absorção passiva de conteúdo pelo aluno. Esses métodos não desenvolvem a percepção do estudante sobre a necessidade de serem desenvolvidas competências indispensáveis para a sua atuação profissional, resumindo a experiência acadêmica a um caráter prescritivo e tecnicista (POWEL; WEEK, 2003). Paralelamente, a figura do professor é sintetizada a um perfil de instrução e condução monocrática do processo de ensino-aprendizagem, evidenciando assimetrias e disfuncionalidades do ensino tradicional de engenharia (CHINAGLIA; SANTOS, 2018).

Para mitigar essas problemáticas, diversos métodos de aprendizagem ativa - onde o aluno é o protagonista do processo educacional - são amplamente discutidos na literatura de docência em engenharia - como a Aprendizagem baseada em Problemas - PBL (SAVIN; HOWELL, 2004; VILLAS-BOAS et al., 2016), em Projetos - PjBL (POWEL; WEEK, 2003; FERNANDES, FLORES; LIMA, 2012), em Cenários - SBL (SAUD et al., 2017; SORIN, 213) - ou em Serviços Comunitários - SvBL (TSANG, 1999; PIAZZA et al., 2019). Esses métodos consistem em adaptar a forma de aprendizagem a situações dinâmicas, de modo a desenvolver o potencial humano além da assimilação de conteúdos técnicos. Além do aperfeiçoamento e capacitação profissional, a aprendizagem ativa destaca a importância da potencialização de competências (NEVES, 2005), que impulsiona a percepção dos estudantes para as reais situações práticas da vida profissional e social além da universidade (VILLAS-BOAS; SAUER, 2019).

Nessa perspectiva, o desenvolvimento de planos de ensino baseados na aprendizagem ativa tornou-se uma condição promissora no contexto da educação brasileira em engenharia. Contudo, eventos históricos - como a pandemia da COVID-19 - explicitam barreiras até então de difícil percepção no contexto do desenvolvimento da aprendizagem ativa, desafiando sua continuidade em um ambiente virtual de ensino-aprendizagem. Nesse primeiro momento, introduziu-se o ensino remoto emergencial (ERE) como uma migração para o ambiente online "transferindo e transpondo metodologias e práticas pedagógicas típicas dos territórios físicos de aprendizagem" (MOREIRA; HENRIQUES; BARROS, 2020, p. 352). Assim, a condução dos métodos ativos necessita de adaptação, que englobe e compreenda a necessidade dos envolvidos de forma direta no processo, como alunos, professores e instituições de ensino (BATES, 2021; MOREIRA; HENRIQUES; BARROS, 2020). Sobre isso, indaga-se até que ponto as estratégias atuais pertinentes à aprendizagem ativa são válidas em um ambiente diferente daquele nas quais foram concebidas? De que forma esta realidade coercitivamente digital pode ser adaptada aos 
princípios da aprendizagem ativa, de modo a garantir os mesmos objetivos de desenvolvimento de competências transversais?

Baseados nessas perguntas de pesquisa, esse estudo objetivou investigar quais adaptações na Aprendizagem baseada em Problemas (PBL) são necessárias para a condução de uma disciplina de Gestão Empresarial para o curso de Engenharia Civil da UFPA de forma remota. Essa temática é substancialmente relevante ao evidenciar como o PBL pode ser implementada sob diferentes circunstâncias tecnológicas, socioeconômicas, socioculturais e sociopsicológicas em situações atípicas, que requerem maior flexibilidade de atividades, carga-horária e desempenho extraclasse. A contribuição dessa pesquisa para a literatura do PBL em tempos pandêmicos é latente, e propõe-se ainda contribuir para a prática de docentes que pretendam adaptar suas metodologias segundo as restrições supracitadas. Espera-se com esse estudo que o processo de aprendizagem ativa não fique restrito às dinâmicas originais de sua concepção, podendo extrapolar os limites informacionais percebidos e se adaptando às novas realidades presentes e futuramente revividas.

\section{ESTUDO DE CASO}

O estudo foi conduzido na disciplina TE02133-Gestão Empresarial, ofertada como componente curricular optativo do curso de Engenharia Civil da Universidade Federal do Pará (UFPA), campus Belém. A turma presencial foi composta por 48 alunos e durou, aproximadamente, oito semanas entre abril e junho de 2016. Já a (primeira) turma remota deverá ser composta por no máximo 30 alunos, a ser ministrada entre agosto e novembro de 2021. A disciplina objetiva capacitar os alunos de engenharia a entender práticas gerenciais em escritórios e canteiros de obras, adaptando métodos, condutas e procedimentos sob diferentes perspectivas da administração - gestão financeira, de pessoas, de segurança, de suprimentos e afins. Segundo recomendações da coordenação acadêmica, o número máximo de alunos por turma é limitado a 30 alunos quando a disciplina for conduzida de forma remota, em virtude das dificuldades impostas controle e gerenciamento de atividades estudantes (BATES, 2021).

A aplicação do método PBL nesta disciplina buscou potencializar nos alunos as oito competências propostas pelas Diretrizes Curriculares Nacionais (DCN's) para os cursos de Engenharia no Brasil (MINISTÉRIO..., 2019). Dentre elas, buscou-se desenvolver as seguintes competências específicas, alinhadas com os objetivos de aprendizagem da disciplina:

I. Habilidade de solucionar problemas;

II. Capacidade crítica;

III. Visão sistêmica de soluções;

IV. Trabalho em equipe;

V. Comunicação e oratória;

Essas competências objetivam potencializar habilidades técnicas e holísticas nos estudantes, tornando o profissional egresso mais adaptado aos cenários e situações do mercado de trabalho e às relações sociais que o mesmo estabelece. O estudo considerou o aluno já possui essas competências, contudo, desenvolvidas em escalas diferentes a partir das características subjetivas de cada indivíduo. Dessa forma, objetivou-se verificar a potencialização das competências através de um método de aprendizagem ativo, uma vez que "potencializar" associa-se a "aperfeiçoar/melhorar aquilo que já existe" (NEVES, 2005). Esse método de aprendizagem ativa já é aplicado pelo professor em outra disciplina obrigatória do curso, TE09076-Legislação e Ética, que vem sendo trabalhada de forma 
remota desde março de 2020, quando se intensificou a pandemia do COVID-19. Portanto, as adaptações sugeridas para a disciplina de Gestão Empresarial se baseia, além da bibliografia citada, na experiência do tutor com o método PBL aplicado nas turmas de Legislação.

\section{MÉTODO}

A condução da disciplina em ambas as turmas foi desenvolvida em quatro etapas:

I. Apresentação do PBL;

II. Identificação dos problemas;

III. Aplicação do PBL;

IV. Apresentação dos resultados do PBL.

A primeira etapa corresponde ao planejamento e organização para introdução do contexto de aprendizagem ativa. As etapas seguintes indicam o desenvolvimento do processo de ensino-aprendizagem através de ciclos semanais de aprendizagem. Cada ciclo do PBL representa a uma fase de aprendizagem, tendo como ponto de partida a identificação dos problemas propostos. A partir dos resultados de cada ciclo, realiza-se uma reflexão sobre a aprendizagem individual sobre o conhecimento adquirido e habilidades desenvolvidas e sobre as competências necessárias aos alunos para realizar as atividades seguintes. Tais reflexões foram realizadas, entre um ciclo e outro com a análise das observações nos encontros, em que se analisavam a frequência dos membros do grupo, o crescimento de participação nas reuniões (exposição de opiniões), o comprometimento com as atividades a serem desenvolvidas e a percepção dos participantes em relação aos objetivos da organização. No ambiente virtual, Bates (2021) indica que esse comprometimento continuo do aluno é prejudicado por fatores externos (restrição tecnológica momentânea ou permanente, inviabilidade financeira de suporte) ou internos (condição psicológica fragilizada, incompatibilidade entre a coexistência de problemas familiares e escolares). Por isso, adaptações devem ser feitas na condução desta metodologia ativa para tornar o aprendizado dos discentes equivalente aos resultados obtidos quando em dinâmicas presenciais.

\subsection{Apresentação do PBL}

A primeira etapa consiste em reuniões (presenciais ou remotas) com o engenheiro responsável pelos canteiros de obras da empresa-participante, objetivando explicar o método PBL, sua adequação ao contexto organizacional e o objetivo do estudo. Além disso, foram definidos a importância do repasse e da confidencialidade das informações, a definição dos direitos/deveres dos alunos e da empresa. Nesta etapa, foi importante entender a cultura da empresa, ou seja, a missão, a visão, as expectativas ou os desejos dos clientes, a análise dos ambientes externos à organização (fatores macroambientais, concorrências, fornecedores e mercado), a análise interna (desempenho das vendas, pontos fortes e fracos) e os objetivos estratégicos.

Na turma presencial, o estudo foi desenvolvido em uma empresa de construção civil de médio porte atuante nos segmentos de obras hospitalares, comerciais e residenciais para clientes públicos e privados na cidade de Belém-PA. A empresa possui um sistema de gestão da produção focado na produção enxuta, com sistema de planejamento e controle da produção (PCP) implementado. Foram realizadas algumas reuniões com o gerente de obras da empresa e o engenheiro responsável pela obra para identificação das necessidades operacionais dos empreendimentos. Os problemas foram identificados 
através de temas afins à temática da disciplina, como controle, planejamento, custos, projeto, etc.

$\mathrm{Na}$ turma remota, pretende-se manter o contato com profissionais atuante no segmento de construção de edifícios, buscando trazer para o contexto das aulas dinâmicas de intervenção semelhantes às já trabalhadas. Um dos fatores que fragilizam o desenvolvimento deste processo é a impossibilidade de transpor momentaneamente a esfera digital do ambiente escolar para vivenciar as práticas descritas pelos convidados em canteiros de obras reais. Essa situação pode e deve ser mitigada ao se trabalhar com 0 máximo de ferramentas e recursos disponíveis para tornar a experiencia de imersão do aluno naquela situação mais próxima possível da realidade - como vídeos das atividades in loco, relatórios de execução e acompanhamento, registros diversos, tours digitais e afins. Por outro lado, se a experiencia prática é reduzida, a potencialização do alcance digital possibilita a interação dos alunos com profissionais cujo encontro presencial seria logisticamente inviável. Essa modalidade de aproximação torna possível que engenheiros e empresas de todo o Brasil (e até do exterior) possam contribuir nas aulas com experiencias, relatos e materiais sobre seus trabalhos práticos, o que enriquece 0 intercambio cultural e profissional do corpo discente.

\subsection{Identificação dos problemas}

$\mathrm{Na}$ turma presencial, participaram da primeira reunião, o mestre-de-obras, o engenheiro residente, o responsável pelo setor de suprimentos e o gerente geral de obras da empresa. Objetivando trabalhar com problemas reais e que estivessem ocorrendo no momento de oferta da disciplina, procurou-se envolver as pessoas que pudessem colaborar na identificação das necessidades da empresa. Neste workshop, foi realizado um brainstorming para a seleção dos problemas com o objetivo de aproveitar ideias de todos os participantes, para depois fazer a triagem. O grupo reuniu os problemas identificados em seis temas (planejamento, segurança, custos, suprimentos, produção e projeto), em ordem respetiva de necessidade atribuída. $\mathrm{O}$ grupo foi dividido em três subgrupos para discutir e hierarquizar os problemas que seriam trabalhados por eles.

$\mathrm{Na}$ turma remota, o processo de mapeamento de temáticas e necessidades de intervenção segue lógica semelhante, visto que as reuniões com o corpo técnico poderão ser mantidas (agora, à distância). Nesse contexto, a depender da natureza da obra, da empresa e dos profissionais envolvidos na identificação dos problemas, outras temáticas também podem ser inseridas além das seis supracitadas, como gestão de pessoas, sustentabilidade, qualidade, entre outros.

\subsection{Aplicação do PBL}

$\mathrm{Na}$ turma presencial, foi apresentado aos alunos o ciclo do PBL e o plano de aulas baseado na ementa da disciplina no qual constava o assunto, objetivo, método e os recursos didáticos necessários. Após a formação dos seis subgrupos, foi sugerido a criação de um ambiente de comunicação e que nele participasse o professor da disciplina, com o objetivo de facilitar troca de informação, sanar dúvidas, agendamentos das visitas ao canteiro de obra, etc. O ciclo do primeiro estudo teve como objetivo apresentar o PBL, o funcionamento do ciclo de aprendizagem, expor suas características, mencionar particularidades e relacionar as necessidades que a metodologia iria exigir da turma. Foi explicado o modelo de avaliação, ressaltando que a frequência e a participação dos alunos durante as aulas seriam importantes no conceito avaliativo. A apresentação da empresa e dos temas à turma foi realizada pelo gerente geral de obras da empresa, que relatou situações, cenários e desafios enfrentados pela companhia, de modo a promover 0 entendimento dos alunos sobre a situação da firma. 
Após isso, houve a distribuição dos estudos de caso por tema para cada grupo. Cada caso relatava um problema real da empresa que deveria ser resolvido pela equipe, em concordância com o conteúdo programático da disciplina e atribuições de um(a) engenheiro(a) civil. No primeiro momento, após a leitura do estudo de caso, os alunos tomavam conhecimento do problema e o discutiam entre si, tentando entender a causa e as suas possíveis soluções. Para isso, foi utilizado um questionário, definido como Relatório Parcial, baseado em Ribeiro (2015), que definia o problema e suas possíveis causas; registro dos conceitos administrativos relevantes para a solução ao problema e o planejamento de como o grupo iria buscar os conceitos (quem, como, o que, e quando).

Esse planejamento era acompanhado pelo professor da disciplina, com a finalidade de checar o cumprimento das funções de cada integrante do grupo. No segundo momento, ou seja, no estudo individual, os alunos buscavam a solução do problema através da pesquisa bibliográfica e/ou consulta a especialistas, fossem profissionais do setor ou outros professores da faculdade. Nos encontros seguintes, os estudantes apresentavam o resultado dos estudos individuais, reuniam-se nos subgrupos e discutiam até chegar à solução do problema. Os encontros ocorriam no próprio canteiro de obras durante vários ciclos até o resultado final.

$\mathrm{Na}$ turma remota, o processo de acompanhamento e desenvolvimento do PBL é semelhante; entretanto, utilizando diversas ferramentas de interação digital para dar suporte. Tanto o ambiente institucional (SIGAA) quanto o utilizado (Google Classroom) possibilitam a interação entre alunos, abertura de fóruns de debate, compartilhamento de mídias, arquivos, atividades avaliativas e qualquer conteúdo pertinente. Nesse contexto, a disciplina extrapola o horário limitado pela coordenação acadêmica e ocorre também de maneira assíncrona nesses ambientes, tornando seu desenvolvimento mais orgânico do que o das turmas presenciais, que obedecem aos horários de classe. Além disso, o gerenciamento desse ambientes virtuais em encontros síncronos também revela determinada desenvoltura por parte dos tutores, que gerencia diversas salas virtuais: uma onde se encontram todos os alunos; e outras onde cada grupo interage de forma privada. Além da habilidade informacional, é exigido do tutor também a habilidade de interagir simultaneamente com diferentes grupos de trabalho, situação de menor suscetibilidade em um ambiente presencial, onde 0 tutor encontra cada equipe individualmente. $O$ acompanhamento das atividades também merece maior cautela, uma vez que a possibilidade de evasão do aluno por motivos alheios à disciplina é iminente nesse contexto pandêmico (BATES, 2021).

\subsection{Apresentação dos resultados do PBL}

$\mathrm{Na}$ turma presencial, conforme os ciclos avançavam, as intervenções propostas eram apresentadas pelos alunos em sala de aula para as demais equipes através de exposição oral, objetivando um compartilhamento de conhecimentos adquiridos, pontos de vista e conclusões. Geralmente o gerente geral de obras participava desses encontros. Uma vez consolidadas as soluções dos ciclos, os alunos partiam para a etapa da avaliação. Essa avaliação consistia no preenchimento de um questionário denominado Formulário de Avaliação do Processo Educacional, do qual consta uma listagem de critérios relacionados ao desenvolvimento das atividades dos encontros tutoriais com suas respectivas definições, baseadas em revisão bibliográfica e principais fontes de evidências. Esses construtos eram: motivação, relevância, integração de conhecimentos, facilidade de obtenção de material, tempo para compleição das atividades, apresentação dos resultados e alcance dos objetivos educacionais. Além disso, qual cada aluno se auto avaliava e avaliava os demais membros de seu grupo. 
Na turma remota, o processo de apresentação dos resultados deve ser mantido, incentivando a proatividade de comunicação e expressão das equipes. Uma questão sensível reflete na exposição do aluno e do seu ambiente familiar ao ativar recursos de voz e vídeo, de modo que a maioria não se sente à vontade para utiliza-los. Isso pode ocorrer em função da coexistência de ambientes pessoal-acadêmico-profissional do aluno, de modo que o mesmo se sinta inseguro de expor-se em determinadas circunstâncias. Dessa forma, toda forma de expressão (oral e escrita) são incentivadas, deixando a turma livre para indicar de que forma os alunos se sentem mais seguros e confortáveis em interagir. Outra questão tange à participação de mais especialistas para avaliar as propostas das equipes, que agora pelo meio remoto possibilita a maior interação de outros profissionais da empresa e até de outros docentes do curso. Os construtos avaliativos devem se mantidos bem como o método de autoavaliação, devendo o tutor atentar para as condições socioemocionais que os estudantes possam demonstrar durante as atividades.

\subsection{Confronto de Ambientes da Aprendizagem}

Para entender as mudanças necessárias no desenvolvimento do PBL para o ensino remoto, utilizou-se as dimensões relacionadas ao ambiente escolar, propostas por Forneiro (2008) e Closs, Mahat e Imms (2021): (i) Física, referindo-se ao ambiente natural, construído, com equipamentos, móveis e sua disposição no espaço; (ii) Funcional, tangente as diferentes formas de se aproveitar e maximizar o potencial destes espaços; (iii) Temporal, relacionada à organização e uso do tempo planejado para o aprendizado e; (iv) Relacional, investigando as relações entre os indivíduos no ambiente de aprendizagem. 0 Quadro 1 indica como essas quatro dimensões foram utilizadas para investigar a adaptação do PBL nas duas formas de ensino.

Quadro 1 - Dimensões de investigação sobre o PBL presencial e remoto

\begin{tabular}{|c|l|}
\hline Dimensão de Análise & \multicolumn{1}{c|}{ Ensino Presencial } \\
\hline Física & $\begin{array}{l}\text { Quais são os espaços necessários ao ambiente de aprendizagem? } \\
\text { Quais são seus elementos necessários? }\end{array}$ \\
\hline Funcional & $\begin{array}{l}\text { Como os espaços são utilizados no processo de aprendizagem ativa? } \\
\text { Como ocorre a avaliação? }\end{array}$ \\
\hline Temporal & Como é dividido o tempo entre os espaços? \\
\hline Relacional & $\begin{array}{l}\text { Há normas de uso do espaço? Quem são os facilitadores nesses } \\
\text { espaços? Como promover a motivação? Como são organizados os } \\
\text { grupos para as atividades? Como é a interação entre os indivíduos? }\end{array}$ \\
\hline
\end{tabular}

Fonte: Os autores. Adaptado de Forneiro (2008) e Closs, Mahat e Imms (2021) 


\section{RESULTADOS E DISCUSSÕES}

Baseado no desenvolvimento da disciplina Gestão Empresarial utilizando o PBL em dois ambientes distintos (presencial e remoto, físico e virtual), construiu-se o Quadro 2, que sucinta as principais adaptações realizadas para a utilização da aprendizagem ativa no contexto do ensino remoto:

\begin{tabular}{|c|c|c|}
\hline \multicolumn{3}{|c|}{ ro 2 - Adaptação do PBL a } \\
\hline Dimensão de Análise & Ensino Presencial & Ensino Remoto \\
\hline Física & $\begin{array}{l}\text { - Sala de aula física - móveis, } \\
\text { projetor, disposição em formato U; } \\
\text { - Pesquisa e atividades do } \\
\text { canteiro de obras -projetos, } \\
\text { documentos, registros, câmera } \\
\text { fotográfica, trena, EPl's. }\end{array}$ & 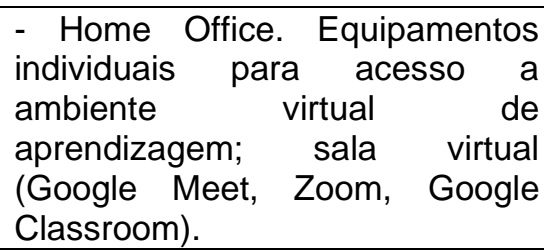 \\
\hline Funcional & $\begin{array}{l}\text { - PBL, ferramentas e estratégias } \\
\text { diversas; (i) filmes, vídeos, sites } \\
\text { interativos, portais de notícias, } \\
\text { redes sociais; (ii) participação de } \\
\text { profissionais especialistas; (iii) } \\
\text { sala de aula invertida; (iv) } \\
\text { seminários. }\end{array}$ & $\begin{array}{l}\text { PBL, ferramentas e estratégias } \\
\text { diversas; (i) filmes, vídeos, sites } \\
\text { interativos, portais de notícias, } \\
\text { redes sociais; (ii) participação de } \\
\text { profissionais especialistas; (iii) } \\
\text { sala de aula invertida; (iv) } \\
\text { seminários. }\end{array}$ \\
\hline Temporal & $\begin{array}{l}\text { - Sala de aula física: abertura e } \\
\text { introdução; discussões das } \\
\text { proponentes nos grupos; } \\
\text { - Canteiro de obras: visitas } \\
\text { agendadas com o tutor e com } \\
\text { gerente da obra; o tempo depende } \\
\text { da função da(s) visita(s), da } \\
\text { disponibilidade de técnico. }\end{array}$ & $\begin{array}{l}\text { - Sala de aula virtual: abertura e } \\
\text { introdução; discussões em grupo; } \\
\text { trabalho em equipe; (i) uso de } \\
\text { várias salas virtuais para o } \\
\text { trabalho de pequenos grupos; (ii) } \\
\text { discussão das proponentes nos } \\
\text { grupos; (iii) trabalho em equipe; } \\
\text { (iv) atividades extraclasse - } \\
\text { filmes/vídeos, leitura, pesquisa. }\end{array}$ \\
\hline Relacional & $\begin{array}{l}\text { - Equipes de trabalho formadas } \\
\text { espontaneamente buscando-se a } \\
\text { diversidade; interação social das } \\
\text { experiências vividas; aprendizado } \\
\text { coletivo pelo compartilhamento de } \\
\text { conhecimento individual; } \\
\text { - Canal de comunicação através } \\
\text { de grupo de WhatsApp; }\end{array}$ & $\begin{array}{l}\text { - Equipes formadas pelos alunos } \\
\text { buscando a diversidade; interação } \\
\text { social das experiências vividas; } \\
\text { aprendizado coletivo através da } \\
\text { partilha de conhecimento } \\
\text { individual. } \\
\text { - Momentos para escutar os } \\
\text { discentes, dando espaço para que } \\
\text { todos se expressem. } \\
\text { - Regras para o uso da sala de } \\
\text { aula virtual; }\end{array}$ \\
\hline $\begin{array}{l}\text { Competências e habilidades } \\
\text { trabalhadas }\end{array}$ & $\begin{array}{l}\text { - Comunicação; } \\
\text { - Resolução de problemas; } \\
\text { - Trabalho em equipe; } \\
\text { - Capacidade crítica; } \\
\text { - Visão sistêmica; } \\
\text { - Autonomia. }\end{array}$ & $\begin{array}{l}\text { - Comunicação; } \\
\text { - Resolução de problemas; } \\
\text { - Trabalho em equipe; } \\
\text { - Capacidade Crítica; } \\
\text { - Visão sistêmica; } \\
\text { - Autonomia; } \\
\text { - Empatia; } \\
\text { - Gerenciamento de tempo; }\end{array}$ \\
\hline Número de alunos & $\begin{array}{l}\text { - } 48 \text { alunos (6 equipes com oito } \\
\text { alunos cada); }\end{array}$ & $\begin{array}{l}\text { - Variável, divididos em equipes } \\
\text { de até quatro quando possui } \\
\text { atividades em grupo }\end{array}$ \\
\hline
\end{tabular}

Fonte: Os autores.

Conforme indica o Quadro 2, as principais dimensões adaptadas pela alteração do ambiente da aprendizagem são a Física, a Temporal e a Relacional. Na dimensão física, os ambientes acadêmicos e de obra devem ser adaptados ao contexto familiar, íntimo dos alunos e professores envolvidos. Essa alteração no cenário onde o individuo se encontra 
gera impactos significativos em sua percepção financeira (despendendo reservas para obter recursos de suporte complementares) e psicológica (gerenciando questões pessoais e acadêmicas simultaneamente). Na visão de Bates (2021), a superação de dificuldades além das evidenciadas no domínio da aprendizagem ativa requerem uma intervenção sistêmica, que extrapola os limites pedagógicos da sala de aula, seja física ou virtual. É necessário que políticas públicas e diretrizes das instituições de ensino superior (IES) atendam satisfatoriamente às demandas sociais de forma a mitigar possíveis efeitos colaterais da sobreposição entre esferas distintas da vida de estudantes e professores. Auxílios para aquisição de internet e computadores pessoais foram adotados como estratégias para reduzir as barreiras socioeconômicas encontradas por alunos da UFPA; contudo, o limitado orçamento das IES federais inviabilizou o atendimento satisfatório a maioria dos estudantes, o que pode comprometer a inclusão dos futuros matriculados na disciplina de Gestão Empresarial. Além disso, a barreira tecnológica está sendo mitigada com técnicos, docentes e alunos através de capacitações emergenciais para utilização de plataformas digitais de ensino e metodologias integradas às tecnologias de informação e comunicação (TIC's).

A dimensão Funcional, embora aparentemente semelhante entre os regimes presencial e remoto, também apresentou adaptações na perspectiva de condução das atividades planejadas. Essas adaptações incluíram, dentre outras, a de análise docente da melhor ferramenta digital para cada contexto do aprendizado, enfatizando quais TIC's deveriam ser acessadas por alunos cujas capacidades de manipulação tecnológica são distintas. Um fator positivo do contexto remoto relaciona-se à possibilidade de participação de especialistas geograficamente distantes da UFPA, integrando o networking dos discentes com outras IES brasileiras. O intercâmbio entre docentes por diversas universidade brasileiras foi facilitado, potencializando a troca de experiências. Todavia, a funcionalidade de atividades como visitas técnicas devem ser repensadas, uma vez que atividades síncronas foram desaconselhadas em virtude das limitações tecnológicas, socioeconômicas ou psicológicas impostas pelas condições que a pandemia do COVID-19 provocou.

$\mathrm{Na}$ dimensão temporal, a perda do contato direto com situações profissionais reais deve ser provavelmente o fator mais sentido por docentes e alunado. Em virtude das restrições sanitárias de circulação não essencial, quaisquer visitas ou atividades que demandassem tempo offline foram desaconselhadas, restringindo a percepção dos alunos sobre a aplicação prática dos conceitos debatidos. Essa deficiência não pode ser contornada, mas mitigada através de palestras de especialistas e dinâmicas no uso de diversas formas de apresentação de conteúdo - filmes, séries, jornais comerciais, podcasts, veículos e formas de comunicação que imprimisse curiosidade nos estudantes. No ambiente virtual, a disposição de alunos em salas virtuais secundárias com somente os membros da mesma equipe também se mostrou um desafio não encontrado no ambiente físico, uma vez que os recursos informacionais atuais não dispõem de ferramentas eficientes para que o tutor consiga gerenciar todas as atividades simultaneamente. Para contornar isto, monitores foram convidados para gerenciar cada sala individualmente, necessitando assim de um maior corpo de assistência para a aplicação do PBL.

$\mathrm{Na}$ dimensão relacional, o conhecimento prévio entre alunos adquire maior importância para o funcionamento da dinâmica virtual, uma vez que no ambiente remoto torna-se mais difícil fortalecer laços pessoais (BATES, 2021). Dessa forma, alunos que já se conhecem tendem a formarem grupos mais rapidamente em ambientes virtuais do que presenciais, onde a situação e o contato direto induzem a abertura para desenvolver novos relacionamentos. Esse fator é importante particularmente nesta componente curricular, que é uma disciplina optativa, ou seja, formada por indivíduos de diversos períodos da 
graduação em Engenharia Civil, o que potencializa a possível exclusão de um aluno que não conheça nenhum outro colega de turma. Para mitigar isso, espaços destinados a interação social devem ser melhor desenvolvidos, de modo que o tutor induza os alunos a desabafarem, indicarem fatos pessoais e compartilharem experiências diversas que podem o não ter associação direta com a disciplina. Essa "quebra de gelo" fortalece a indicação da interação entre alunos e fomenta possíveis relacionamentos extraclasse - mesmo que ainda de forma exclusivamente virtual. A definição da dinâmica da sala virtual também merece atenção - de modo a explicar para o aluno como as aulas podem proceder. Seja pelos recursos disponíveis - como levantar a mão, desenhar no Jamboard - ou pela indicação da sequência de exposição de ideias, é necessário que haja a clara definição das condutas dentro do ambiente virtual - uma vez que o controle por parte do tutor é potencialmente reduzido em relação à sala de aula física.

Dessa forma, em ambas situações (presencial ou remoto), as seguintes competências podem ser trabalhadas com os alunos: comunicação, resolução de problemas, trabalho em equipe, capacidade crítica, visão sistêmica e autonomia. As diferenças entre os ambientes reside em como elas poderão ser manifestadas, por exemplo, a comunicação no ambiente presencial indica a capacitação verbal e não verbal - algo que no ambiente virtual não é uma condição direta, haja vista que a utilização do vídeo e voz não são obrigatórios. Por outro lado, a autonomia no ambiente virtual é potencializada ao exigir que o aluno melhore a busca pelo conhecimento e tenha maior dificuldade em discuti-lo ou analisa-lo, agora dependendo necessariamente de uma TIC para avançar no aprendizado. No ambiente virtual, também se verificou o desenvolvimento de competências ligadas à empatia e ao gerenciamento de tempo. A primeira está associada a ser colocar no lugar do outro estudante/professor durante momentos de luto, dificuldades ou alegrias, emoções corriqueiramente vividas por aqueles que experienciaram os efeitos adversos da pandemia. Já a segunda depreende uma capacidade de conciliação entre as atuações pessoais, profissionais e acadêmicas com maior destreza, uma vez que estas atividades, por se desenvolverem no mesmo ambiente físico - o lar - acabam por necessitarem uma atenção quase simultânea, obrigando alunos e professores a definir hierarquias de prioridade no desenvolvimento de diversas atividades, algo que previamente era regulado de forma intuitiva pelo lugar em que o indivíduo se encontrava presencialmente.

\section{CONCLUSÃO}

Considera-se que esse estudo cumpriu com o objetivo de investigar quais adaptações na Aprendizagem baseada em Problemas (PBL) são necessárias para a condução de uma disciplina de Gestão Empresarial para o curso de Engenharia Civil da UFPA de forma remota. O estudo indicou que as estratégias utilizadas no ambiente físico devem ser adaptadas para o contexto virtual considerando as diferentes restrições tecnológicas, socioeconômicas e socioemocionais que os indivíduos encontram. As principais adaptações dizem respeito à disposição de experiências profissionais práticas, interação com profissionais de regiões geográficas distantes, gerenciamento do tempo entre diferentes atividades, empatia com acontecimentos pessoais alheios e adaptação dos recursos e estratégias de avaliação. A adaptação dos princípios da aprendizagem ativa do ambiente presencial para o remoto, através deste estudo de caso, evidenciou que o desenvolvimento de competências transversais é possível e ocorre de maneira própria, em função da aptidão de interação social dos indivíduos com o grupo inserido e da proficiência com as tecnologias necessárias para a condução das atividades. Essa adaptação 
potencializa competências como autonomia e empatia, mas pode prejudicar a capacidade de comunicação se esta não for trabalhada através da múltiplas formas de expressão, respeitando - entretanto - a diversidade sociológica e socioemocional dos alunos.

Dessa forma, essa pesquisa contribui para o estado da arte sobre a utilização de métodos de aprendizagem ativa em ambientes virtuais, indicando cenários de adaptação dos procedimentos já consolidados para manutenção dos processos ativos de conhecimento. Além disso, há uma contribuição prática para outros docentes que utilizem tais metodologias, indicando caminhos a serem trilhados nesse tipo de ambiente e as eventuais dificuldades encontradas. Para trabalhos futuros, sugere-se avançar na investigação das dimensões de análise individualmente, destacando como cada uma delas é articulada dentro de um contexto pandêmico e potencialmente replicada em cenários futuro pós-pandemia. Essas considerações podem não somente auxiliar educadores a organizar formas remotas de conduzir ambientes ativos de aprendizagem, como também incorporar os benefícios destas em uma realidade próxima e aperfeiçoada.

\section{REFERÊNCIAS}

BARBALHO, S. C. M., REIS, A. C. B., BITENCOURT, J. A., LEÃO, M. C. A., SILVA, G. L. A Project Based Learning approach for Production Planning and Control: analysis of 45 projects developed by students. Production, v. 27, n. e20162259, 2017. DOI: http://dx.doi.org/10.1590/0103-6513.225916.

\section{BATES, T. A. W. Appendix 1: Building an effective learning environment, A.2 What is} a learning environment? Disponível em:

https://opentextbc.ca/teachinginadigitalage/part/chapter-5-building-aneffective-learningenvironment/. Acesso em: 15 mai. 2021.

CLOSS, L.; MAHAT, M.; IMMS, W. Learning environments' influence on students' learning experience in an Australian Faculty of Business and Economics. Learning Environments Research, p. 1-15, 2021. https://doi.org/10.1007/s10984-021-09361-2.

CHINAGLIA, E. F., SANTOS, R. B. B. Aprendizagem ativa para turmas grandes em salas de aula convencionais. Educação em Engenharia, v. 37, n. 2, p. 3-11. 2018. DOI: http://dx.doi.org/10.5935/2236-0158.20180009.

FERNANDES, S.; FLORES, M. A.; LIMA, R. M. Aprendizagem baseada em projetos interdisciplinares no ensino superior: implicações ao nível do trabalho docente. In: Fourth International Symposium on Project Approaches in Engineering Education (PAEE'2012). 2012. p. 227-236.

FORNEIRO, M. L. I. Observación y evaluación del ambiente de aprendizaje em educación infantil: Dimensiones y variables a considerar. Revista Iberoamericana de educación, $n$. 47, p. 49-70, 2008. Disponível em:

https://coleccion.siaeducacion.org/sites/default/files/files/ambientes de aprendizaje maria lina iglesias rie47 12352.pdf Acesso em: 15 mai. 2021.

LIMA, R. M., DINIS-CARVALHO, J., SOUSA, R. M., AREZES, A., MESQUITA, D. Development of competences while solving real industrial interdisciplinary problems: a successful cooperation with industry. Production, v. 27, n. e20162300. 2017. DOI: http://dx.doi.org/10.1590/0103-6513.230016. 
MINISTÉRIO DA EDUCAÇÃO - MEC. Resolução n.ㄹ 2, de 24 de abril de 2019: Institui as Diretrizes Curriculares Nacionais do Curso de Graduação em Engenharia. 2019.

Disponível em

http://portal.mec.gov.br/index.php?option=com docman\&view=download\&alias=109871pces001-19-1\&category slug=marco-2019-pdf\&Itemid=30192 Acesso em 15 mai. 2021.

MOREIRA, J. A. M.; HENRIQUES, S.; BARROS, D. Transitando de um ensino remoto emergencial para uma educação digital em rede, em tempos de pandemia. Dialogia. Disponível em: https://periodicos.uninove.br/dialogia/article/view/17123 Acesso em: 15 mai. 2021.

NEVES, R. M. Modelo de Capacitação de gerentes intermediários na construção civil baseado na ABP. Tese (Doutorado) - Curso de Engenharia Civil. Universidade Federal do Rio Grande do Sul, Porto Alegre, Brasil. 2005.

PIAZZA, D.; BARRETO, L. T. P.; POLETTO, M.; BERTÉLI, M. O.; PESSIN, N.; CORNELLI, R.; BRANDALISE, R. N.; Trabalho Discente Efetivo como meio de fomentar Autonomia do Estudante na disciplina de Introdução à Engenharia. In: Anais do XLVII Congresso Brasileiro de Educação em Engenharia. Fortaleza: ABENGE, 2019.

POWELL, P. C.; WEENK, W. Project-led engineering education. Utrecht: Lemma Publishers, 2003.

RIBEIRO, L. R. C. A Aprendizagem Baseada em Problemas (PBL): Uma Implementação na Educação em Engenharia na Voz dos Atores. 236. Tese (Doutorado) - Curso de Educação. Universidade Federal de São Carlos, São Carlos, 2015.

SAUD, M. S.; KAMIN, Y.; LATIB, A. A.; AMIN, N. F. A Conceptual Model of Scenario Based Learning for Developing Higher Order Thinking Skills in Engineering Education. Advanced Science Letters, v. 23, n. 1, 194-196, 2017.

SAVIN-BADEN, M.; HOWELL, M. C. Foundations of problem-based learning. New York: McGraw-Hill Education, 2004.

SORIN, R. Scenario-based learning: Transforming Tertiary Teaching and Learning. Proceedings of the 8th QS Asia Pacific Professional Leaders in Education Conference, 71-81. Bali, 2013.

TSANG, E. (Ed.). Projects that matter: Concepts and models for service-learning in engineering (Vol. 5). Stylus Publishing, LLC., 1999.

VILLAS-BOAS, V.; MARTINS, J. A.; GIOVANNINI, O.; SAUER, L. Z., BOOTH, I. A. S. (Org.). Aprendizagem baseada em problemas: estudantes de ensino médio atuando em contextos de ciência e tecnologia. 1ed. Brasília: ABENGE, 2016.

VILLAS-BOAS, V.; SAUER, L. Z. Aprendizagem Ativa na Educação em Engenharia em tempos de Indústria 4.0. In OLIVEIRA, V. F. A. Engenharia e as Novas DCNs: oportunidades para formar mais e melhores engenheiros. Rio de Janeiro, RJ: GEN/LTC, 2019. 


\title{
ACTIVE LEARNING FOR REMOTE TEACHING: PROPOSAL FOR THE DISCIPLINE OF BUSINESS MANAGEMENT AT UFPA
}

\begin{abstract}
The COVID-19 pandemic made remote teaching a reality in education, proposing a latent challenge to those inserted in the context of active learning; however, we have not yet identified how to manage this adaptation of the face-to-face world to the digital one without compromising the learning objectives. Thus, this work aimed to investigate which adaptations in Problem Based Learning (PBL) is necessary to conduct the Business management discipline remotely. The method consisted of planning the $P B L$ in a face-to-face class (pre-pandemic) and an online class (during the pandemic) in four stages: I) presentation of the PBL; II) Identification of problems; III) Application of the PBL and; IV) Presentation of PBL results. The face-to-face and remote environments were evaluated in these four stages from the physical, functional, temporal, and relational dimensions - seeking to identify the differences in procedures, attitudes, and activities inherent to learning. The results indicated that the central adaptations are related to the experience of the professional practice environment - such as visits to construction sites, interaction with geographically distant professionals through video calls, the greatest need for time management between academic and personal activities, in addition to empathy with other people's events. Skills such as autonomy and empathy are enhanced in the virtual environment, while communication needs more planning without invading the student's personal space. The study concluded that the adaptation of active learning to the virtual environment is possible as long as the socio-economic and socio-emotional conditions in which the participants find themselves are known and integrated.
\end{abstract}

Keywords: COVID-19. PBL. Professional Practice. Empathy. 